From the authors:

We wish to thank R.J. Kurukulaaratchy and co-workers for their positive response to our article [1]. We were happy to see that our paper encouraged the Isle of Wight Birth Cohort (IOWBC) to assess the prognosis of early recurrent wheeze into the beginning adulthood. As the corresponding findings in the IOWBC, with its high 18-year follow-up rate of 90\% [2], are in line with those from our Environment and Childhood Asthma Study, it strengthens the message that the longer term prognosis of early recurrent wheeze might not be as favourable as previously conceived $[3,4]$. Furthermore, the findings underline the importance of long-running birth cohorts enabling studies where recall bias is limited. As recent retrospective reports suggest that adult chronic obstructive pulmonary disease may have an early-life origin $[5,6]$, the need for long-term prospective cohorts to address this specific question is obvious.

With the additional data now presented by R.J. Kurukulaaratchy and co-workers on the natural course of early life wheeze, we suggest a reconsideration of the possibility of diagnosing asthma in preschool children as well as caution when addressing the potential favourable long-term prognosis of early recurrent wheezy illness.

○ @ERSpublications

We should reconsider diagnosing asthma in preschool children and be cautious with the prognosis of early wheeze http://ow.ly/qkD5S

Vegard Hovland $^{1,2}$, Amund Riiser ${ }^{1,2}$, Petter Mowinckel ${ }^{1}$, Kai-Håkon Carlsen ${ }^{1,2,3}$ and Karin C. Lødrup Carlsen ${ }^{1,2}$ ${ }^{1}$ Oslo University Hospital, Dept of Paediatrics, Oslo, ${ }^{2}$ University of Oslo, Faculty of Medicine, Institute of Clinical Medicine, Oslo, and ${ }^{3}$ Norwegian School of Sport Sciences, Oslo, Norway.

Correspondence: V. Hovland, Dept of Paediatrics, Oslo University Hospital, NO-0407 Oslo, Norway. E-mail: uxhovv@ous-hf.no

Received: June 182013 | Accepted: June 202013

Conflict of interest: None declared.

\title{
References
}

1 Hovland V, Riiser A, Mowinckel P, et al. The significance of early recurrent wheeze for asthma outcomes in late childhood. Eur Respir J 2013; 41: 838-845.

2 Roberts G, Zhang H, Karmaus W, et al. Trends in cutaneous sensitization in the first 18 years of life: results from the 1989 Isle of Wight birth cohort study. Clin Exp Allergy 2012; 42: 1501-1509.

3 Martinez FD, Wright AL, Taussig LM, et al. Asthma and wheezing in the first six years of life. The Group Health Medical Associates. N Engl J Med 1995; 332: 133-138.

4 Wennergren G, Amark M, Amark K, et al. Wheezing bronchitis reinvestigated at the age of 10 years. Acta Paediatr 1997; 86: 351-355.

5 Shirtcliffe P, Marsh S, Travers J, et al. Childhood asthma and GOLD-defined chronic obstructive pulmonary disease. Intern Med J 2012; 42: 83-88.

6 Svanes C, Sunyer J, Plana E, et al. Early life origins of chronic obstructive pulmonary disease. Thorax 2010; 65: $14-20$.

\section{Can overweight/obesity and smoking have combined effects on bronchial hyperresponsiveness?}

\author{
To the Editor:
}

We read with interest the article by JUUSELA et al. [1], which showed a significant risk factor for bronchial hyperresponsiveness (BHR) with a dose-dependent pattern and which underlined that BHR severity increases with increased smoking (pack-years) in an adult sample of the general population. Unfortunately, in their study the authors did not analyse a possible additional influence of overweight/obese status on BHR. In fact, several researchers have shown that the overweight/obese condition may be a risk factor for BHR (adjusted for smoking), both in healthy subjects and, in particular, in asthmatics [2-4]. A fair amount 